Article

\title{
Fostering Resident Pro-Environmental Behavior: The Roles of Destination Image and Confucian Culture
}

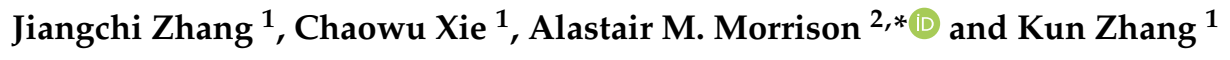 \\ 1 College of Tourism, Huaqiao University, Quanzhou 362021, China; zjc87858480@163.com (J.Z.); \\ xiecwu@126.com (C.X.); kunzhang1996@163.com (K.Z.) \\ 2 Department of Marketing, Events and Tourism, Business School, University of Greenwich, Old Royal Naval \\ College, Park Row, London SE10 9LS, UK \\ * Correspondence: a.morrison@gre.ac.uk
}

Received: 6 November 2019; Accepted: 9 January 2020; Published: 14 January 2020

\begin{abstract}
Residents are important participants and stakeholders in destination development. Identifying factors that assist in predicting resident pro-environmental behavior (PEB) may contribute to enhanced sustainability. Based on a traditional Chinese culture, this research constructed a model of resident PEB by introducing pro-environmental destination image (PEDI) and Confucianism as the independent and moderating variables, respectively. The structural equation modeling for 402 residents indicated the model had a satisfactory level of predictive power for PEB. The results showed that: (1) PEDI positively affected residents' environmental identity, pro-environmental attitudes, and PEB; (2) environmental identity and pro-environmental attitudes completely mediated the impact of PEDI on residents' PEB; and (3) Confucian culture had a positive U-shaped moderating effect in the relationships among these four variables. Overall, these findings advance the understanding of the formation of PEB in Confucian culture and provide theoretical and practical implications for fostering residents' PEB.
\end{abstract}

Keywords: pro-environmental destination image (PEDI); environmental identity; pro-environmental attitudes; Confucian culture; pro-environmental behavior (PEB); residents

\section{Introduction}

A destination's environment is an important attraction in tourism and directly affects tourists decision-making and experiences. In addition to the positive impact of tourism, serious adverse consequences for destinations result from environmental pollution, destruction of natural resources, and damage to cultural-heritage sites [1-4]. Thus, sustainability concerns are an ever-present research theme that is one of the fastest-growing areas of discussion in the tourism literature. Residents are important stakeholders in tourism development and have the strongest bonds with destinations because their livelihoods and well-being are closely linked to the quality of the environment. Moreover, residents' behaviors and activities have a direct, comprehensive, and deep impact on the quality of the destination environment [5]. Therefore, fostering residents' pro-environmental behavior (hereinafter named as PEB) can be one of the foundations for sustainable destination development.

Prior studies have indicated that PEB is a significant issue in environmental research. Key theories such as the theory of planned behavior [6-9]; norm-activation model [5,6]; value-belief-norm theory [7]; and place attachment [10] have been employed to predict environmental behavior. Environmental attitudes, individual beliefs, emotions, intentions, and behaviors related to the environment $[11,12]$ are recognized as key factors in the prediction of environmental behavior. The identity process of environmentally responsive behavior and the use of identity theory to understand environmental 
behavior have gradually attracted more attention in sociology. For example, Stets and Biga [13] introduced identity theory into environmental sociology and suggested that it was positively associated with pro-environmental attitudes and PEB. Additionally, Nunkoo and Gursoy [14] asserted, through a theoretical analysis, that residents' environmental identity was a personal identity when interacting with the natural environment, which influences their attitudes toward the impact of tourism and their support behavior. Thus, the environmental "identity-attitude-behavior" theoretical framework has become an important theoretical basis for research.

Residents' PEB may involve altruism and collective action. These represent quasi-public goods and pro-social behavior with an "externality" $[15,16]$. When people think their actions have a limited influence on public problems, they can have the desire to "hitch a ride" [17]. Accordingly, even if residents have positive environmental awareness and pro-environmental intentions, their PEB may not be engaged because they need to bear costs alone or because they perceive a low contribution of their behavior [18]. For this reason, it is appropriate to explore PEB when considering external contextual factors. The theory of attitude-context-behavior suggests that environmental attitudes and external contextual factors act in combination to influence environmental behavior [19]. In addition, the physical environment, which is constituted by specific space and components, provides an activity site for certain groups of people and supports specific behavioral patterns. The activity site and specific behaviors constitute a behavioral setting [20,21]. It is necessary and important to explore residents' PEB from the perspectives of behavioral settings and contextual factors. The provision of PEB settings and positive environmental impressions may be significant factors in motivating residents' $\mathrm{PEB}$, but this proposition has not been sufficiently explored.

Culture involves the values and norms that are reflected in individual behaviors [22]. Residents' PEB and regular activities are also influenced by traditional culture. For example, residents with weak environmental awareness may engage in PEB because of the pro-environmental expectations of other people. In the Chinese context, Confucianism is a traditional culture and provides foundational values that have a profound influence and long history. Confucianism is also a prominent symbol of Chinese culture that differs from other countries $[23,24]$. Prior research explores the ongoing influence of Confucian culture on consumer behavior [25], word-of-mouth communication of travel apps [26], and tourist behavior [27]. However, the relationship between residents' PEB with respect to destinations and Confucian culture has not been thoroughly investigated in previous studies. Because of the widespread and continuous influence of this culture, the effect of Confucianism on Chinese residents' environmental behavior needs to be empirically examined, since this has potentially significant theoretical and practical implications for the motivation of Chinese residents' PEB.

Therefore, reflecting the perspectives of PEB setting and contextual factors, the primary research goal was to construct an integrated model by utilizing PEDI and Confucian culture to explore the formation of residents' PEB in China. The specific objectives were to: (1) examine the effect of PEDI on the environmental "identity-attitude-behavior" research framework; and (2) explore the moderating effect of Confucian culture in the relationships among these four variables. The findings could provide a new research direction to examine resident PEB and suggest strategies for involved organizations to foster resident PEB and achieve sustainable destination development.

\section{Literature Review and Research Hypotheses}

\subsection{Pro-Environmental Destination Image (PEDI)}

Image has been defined as overall impressions that individuals hold of specific objects [28,29]. The notion of PEDI originates from the destination image concept and can be defined as overall positive environmental impressions that people have of particular destinations [30]. Allied concepts include green destination image, environmentally-friendly image, and ecological image [31,32] and they represent a collection of individuals' perceptions, emotions, and impressions of the destination environment. PEDIs are influenced by the PEB setting and the perceptions that destination management 
organizations (DMOs) and protected areas attempt to create through pro-environmental measures such as landscape protection, ecological promotion and publicity, and waste recycling [30]. In addition, some DMOs, especially local government agencies, introduce policies, regulations, and other initiatives to develop, promote, and enhance a pro-environmental image. Several studies have regarded the concept of the destination image as an antecedent of attitudes [33], motivations [30], destination attachment [32], and revisit intentions [34,35]. Accordingly, as a component of destination cognitive images, pro-environmental images affect individuals' perceptions, attitudes, and behaviors in relation to the environment.

Identity is the process by which individuals develop a sense of belonging to the environment and the people and things within it [36]. Environmental identity is conceptualized as a personal identity and can be defined as an "experienced social understanding of who we are in relation to, and how we interact with the natural environment" [37]. It consists of a set of meanings that people sense when interacting with the natural environment [11]. In other words, residents' environmental identity is the self-characteristic meaning generated from interactions between residents and their living environments [38]. It reflects residents' psychological state of belonging to the destination environment.

According to social information processing theory, individuals will adjust their beliefs, attitudes, and behaviors based on the information provided by the surrounding environment and adapt to their social context [39]. The information perception structure in a pro-environmental context differs significantly from the structure in an ordinary context. For example, protected areas and DMOs can motivate residents to interact with the natural environment by disseminating eco-friendly information and creating PEB settings. When residents perceive the pro-environment setting and image provided by the destination, they may organize, absorb, and assimilate this information in their interactions with the environment, which strengthens their environmental identity. Therefore, Hypothesis 1a was proposed as:

Hypothesis H1a. PEDI has a significant positive impact on residents' environmental identity.

Eagly and Chaiken [40] believe that attitude is a psychological tendency expressed by the degree of favor or disfavor of a specific object. Environmental attitude is a stable psychological tendency towards environmental protection and a collection of individual beliefs, emotions, intentions, and behaviors related to the environment [11,12]. Specifically, residents with pro-environmental attitudes are concerned about the negative impacts of their actions on the ecological environment and commit to behaving in a way that does not harm it [41].

Generally, contextual factors are important in predicting environmental attitudes [19]. The external environment has a stimulating effect on attitudes and so does PEDI. Additionally, people prefer compliant behaviors to reduce cognitive effort and resource consumption, and they may change their attitudes to adapt to the external environment $[20,21]$. In pro-environmental destinations, residents can access eco-friendly information and perceive pro-environmental settings provided by the destination, which influences their pro-environmental attitudes through image recognition. That is, residents adjust their pro-environmental attitudes to embed the pro-environmental images they perceive. Therefore, Hypothesis $1 \mathrm{~b}$ was as follows:

Hypothesis H1b. PEDI has a significant positive impact on residents' pro-environmental attitudes.

In this research, PEB refers to the actions taken by individuals or groups that promote or result in the sustainable development of natural resources [42]. Residents can be strategic participants in the construction of a destination's ecological image, and their PEB may strongly bond with sustainable destination development [5].

For residents' PEB, the framing effect indicates that different types of feedback framing produce varying motivations in individuals [43]. Accordingly, the pro-environmental framing effect can motivate individuals to be altruistic, which increases their willingness to make efforts towards 
environmental protection, even if the benefits of PEB are minor [44]. Additionally, residents' perception of a pro-environmental image will inevitably involve complex cognitive stages such as association, and thinking and comparison of the surrounding environment, and then lead them to adapt their behaviors to the environment. Therefore, residents may adjust to unbalanced environments by demonstrating 'unfriendly' environmental behavior under poor environmental conditions. Alternatively, residents may reduce their improper environmental behavior in pro-environmental scenarios and may strive to show PEB to enhance the characteristics of the external environment [16,21,45]. Therefore, Hypothesis 1c was proposed to be:

Hypothesis H1c. PEDI has a significant positive impact on residents' PEB.

\subsection{Environmental Identity and Pro-Environmental Attitudes}

According to the stimulus-organism-response (SOR) framework, external stimuli (S) generate individuals' internal states $(\mathrm{O})$, and then trigger their behavioral responses $(\mathrm{R})$ [46]. Stimuli can be tangible or intangible and can trigger individuals' cognitive and emotional states, which induce the behavioral responses of approach or avoidance $[47,48]$. Internal states can mediate the relationship between stimuli and responses. From the perspective of image creation, PEDIs are fostered by protected areas and DMOs through the sorting and refining of various pro-environmental elements that are selectively disseminated to residents, which affect residents' subjective perceptions of the objective environmental elements of the destination [30]. Accordingly, the subjective perception of pro-environmental scenarios and eco-friendly stimulation may trigger residents' internal states in relation to the environment, such as identity, attitudes, and emotions, which then determine residents' PEB. For these reasons, residents' environmental identity and pro-environmental attitudes may mediate the influence of PEDI on PEB. Therefore, Hypotheses $2 a$ and $2 b$ were articulated as:

Hypothesis H2a. Environmental identity plays a mediating role in the relationship between PEDI and residents' $P E B$.

Hypothesis $\mathbf{H} 2 \mathbf{b}$. Pro-environmental attitudes play a mediating role in the relationship between PEDI and residents' $P E B$.

\subsection{Confucian Culture}

Cultural values occupy a central position in personal cognitive systems and are the foundations of individual decision-making and behavioral patterns [49]. Confucianism is said to be "the critical philosophical system that is embedded in the mind of every Chinese person" [50], and individual decision-making and behavioral patterns follow the values and ideology of Confucian culture [25-27].

In terms of environmental protection, Confucianism advocates the eco-friendly concepts of "benevolence and love to all creatures" and "harmony of heaven, earth and man". The concept of "benevolence and love to all creatures" requires individuals to develop an eco-friendly awareness and to treat all things in the world kindly, such as birds, animals, plants and trees. The concept of "harmony of heaven, earth and man" holds that people and nature are intrinsically connected [51]. Thus, people and things should follow the laws of nature and achieve harmony between humans and nature. Therefore, it is thought that Confucian culture has a powerful and deep influence on residents' environmental awareness and behavior [52]. Scholars have asserted that cultural values affect travelers' PEB [7], or as a type of moderator, cultural values predict household waste management behavior [53].

Confucian culture has broad connotations and characteristics. Some of the aspects are behavior-identity matching, Mianzi (face), and listening to others [24,54,55]. Behavior-identity matching emphasizes the impact of social identity, family identity, and other personal identities on individual 
behavior [56]. Mianzi indicates individuals' needs for self-esteem and reputation in interpersonal interactions [57]. Listening to others reflects individuals' dependence on other people or organizations and subsequent 'herd' behavior [24,55]. These aspects of Confucian culture are relevant because they are both used in the predication of individuals environmental behavior $[23,24]$ and are closely related to residents' environmental behavior. For example, residents with high behavior-identity matching may tend to implement environmental behaviors that match their personal identity in a pro-environmental context. Residents with a high need for Mianzi may strive to adapt to a PEB setting and thus increase their willingness to be eco-friendly to maintain their overall reputation and self-image in the eyes of other people $[24,26]$. Residents with the trait of listening to others may consciously or unconsciously adopt the opinions of the majority and be more willing to adopt pro-environmental attitudes in a PEB setting.

In summary, Confucian culture has had a powerful and continuous influence on Chinese environmental values and has become the foundational norm of Chinese environmental behavior. Confucianism is believed to have a moderating effect on the relationships among PEDI, environmental identity, pro-environmental attitudes, and PEB. Therefore, Hypotheses $3 a, 3 b$, and $3 c$ were proposed as:

Hypothesis H3a. Confucian culture moderates the influence of PEDI on residents' environmental identity.

Hypothesis H3b. Confucian culture moderates the influence of PEDI on residents' pro-environmental attitudes.

Hypothesis H3c. Confucian culture moderates the influence of PEDI on residents' PEB.

The proposed conceptual research model for the influences (four variables) on residents' PEB (dependent variable) is shown in Figure 1.

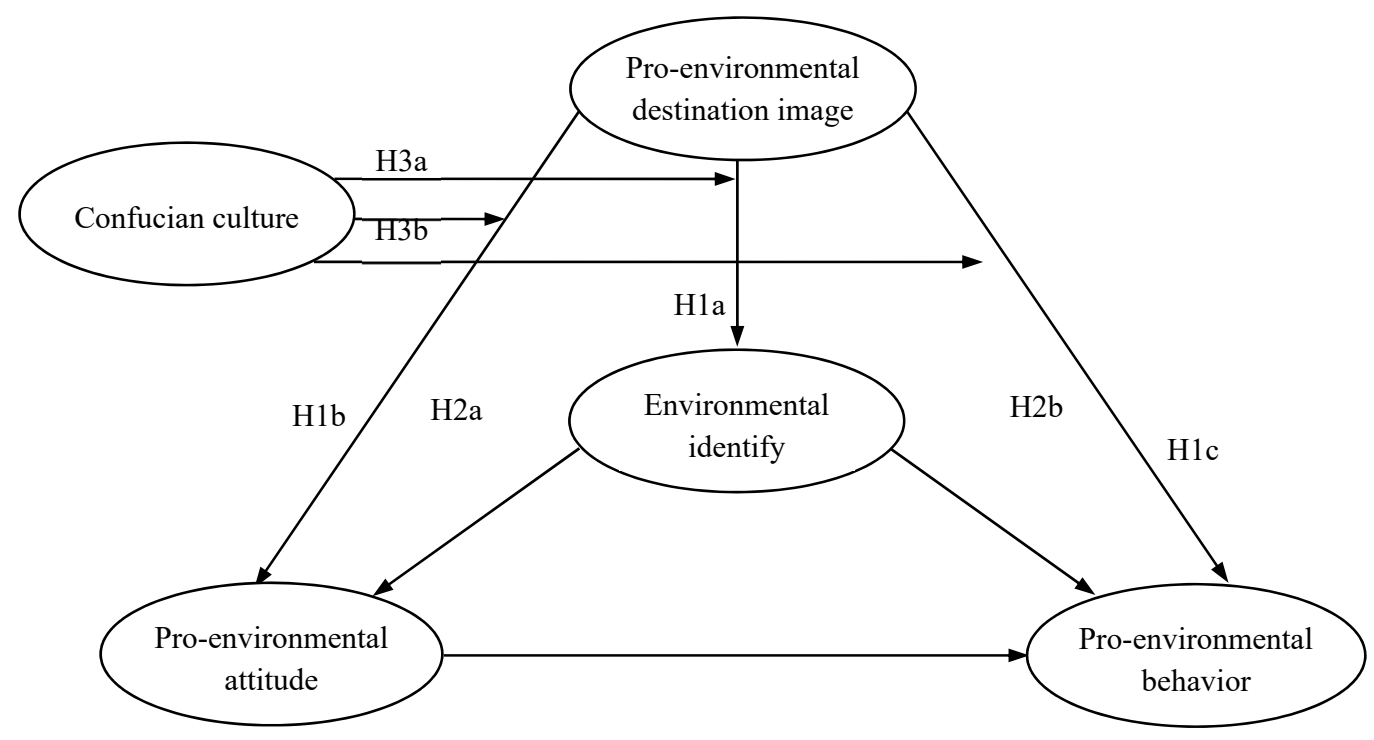

Figure 1. Conceptual research model.

\section{Methodology}

\subsection{Questionnaire Design}

All variables were measured with previously validated scales that have been widely employed in environmental research. Some items were slightly modified according to the research context to make them easier for the respondents to understand. By using the back-translation method [58], the English scales were converted into Chinese versions and then translated back into English with a team that consisted of three management professors (two Chinese and one English) to ensure content validity. 
Each variable was measured on a seven-point Likert scale ranging from 1 (strongly disagree) to 7 (strongly agree).

The questionnaire comprised two parts: the first included demographic characteristics of residents (gender, age, education, and monthly incomes); and the second was the scales for five variables. Four items (including effective green development and construction, well-preserved natural environments, various kinds of breeding programs for animals and plants, and many opportunities to experience nature) based on Lee and Jeong [30] were used to measure PEDI. Five items (including concern for the natural environment, being dependent on the natural environment, being protective of the natural environment, being an advocate of the natural environment, and being connected to the natural environment) based on Stets and Biga [13] as well as Nunkoo and Gursoy [14] measured environmental identity.

Pro-environmental attitudes included five measurement items from Shin et al. [59]: "It is important to me that the products I use don't harm the environment", "I consider the potential environmental impact of my actions when making many of my consumption decisions", "I am concerned that my behavior will damage the environment", "I would describe myself as environmentally responsible", and "I am willing to be inconvenienced in order to take environmentally sustainable actions."

Four items (including willingness to accept environmental policies, maintain environmental quality, handle my own garbage, and tell my friends not to damage the environment) related to PEB were based on Ramkissoon, Smith, and Weile's [60] research.

Confucian culture was measured by using the instrument developed by Zhang [53] and was treated as a first-order factor comprised of the three aspects of behavior-identity matching, Mianzi, and listening to others. The following items were employed to measure behavior-identity matching: "an individual's consumption behavior should match his/her social status", "an individual's clothing should match his/her social status", and "an individual's actions should match his/her social status". The following items were used to measure Mianzi: "I will not tell my family and friends when I lose Mianzi", "I will avoid buying cut-price goods in front of my colleagues", and "When I go shopping with a friend who is richer than me, I will choose an upscale store." The following items were utilized to measure listening to others: "modesty helps one go forward, whereas conceit makes one lag behind", "teachers" instructions are very important", and "I will consider the advice of the people around me when I am making decisions".

\subsection{Data Collection and Sampling}

A combination of online and offline surveys was used to collect data from three destinations (Xiamen, Quanzhou, and Guiyang) through convenience sampling from December 2018. Xiamen was ranked 9th in China National Tourism Administration's top city destinations list in 2018. Quanzhou is an important destination and port city on the southeast coast of China. Guiyang is a recognized destination with rapid tourism development in southwest China. Recently, these cities have been striving to build environmentally-friendly tourist destinations, so it was appropriate to choose them for data collection.

The validity of the data was ensured by informing respondents about the research context and by guaranteeing anonymity. The online survey was conducted on Wenjuanxing [61] (www.wjx.cn), which is a marketing website in China and is widely accepted by international journals for data collection. A hyperlink to this site was posted on a WeChat group of local residents, an online social space. For the offline survey, a research team of five people collected questionnaires in a face-to-face format. The team was trained to know the research purpose, target respondents, and utilize anonymity measures.

To ensure the reliability of each scale, a pilot test was conducted in Xiamen and Quanzhou, and 120 valid questionnaires were collected. The results showed that the Cronbach's $\alpha$ of each construct ranged from 0.776 to 0.814 , and the Cronbach's $\alpha$ of the overall questionnaire was 0.887 , which was above 0.7 and indicated good internal consistency. A total of 501 questionnaires were collected through the formal survey. After removing the invalid questionnaires with repetitious answering patterns, 
random writing, and multiple missing values, there were 402 valid responses, yielding an effective response rate of $80.2 \%$. Among the respondents, there were more males than females ( $53.5 \%$ vs. $46.5 \%$ ). Regarding age, $52.0 \%$ were $18-25$ years old, and $31.3 \%$ were $26-35$ years old. Almost $80 \%$ of the respondents had graduated from junior college or higher, and the largest group had a monthly income of up to RMB 5000 (67.9\%).

\section{Results}

\subsection{Common Method Variance (CMV)}

This study controlled for CMV by pre-setting multiple procedures. First, the order of the independent and dependent variables was changed by placing the items in the reverse direction. Second, there were no incorrect answers in the measurement items, and anonymity was assured to encourage respondents to express their true feelings. After the data were collected, Harman's single-factor test was employed by entering all items into a principal component analysis without rotation. The results showed that the KMO index was 0.871 , and the first principle component explained only $28.7 \%$ of common method variance, which was under the recommended $40 \%$ threshold [62]. Therefore, CMV was not a major concern with this research.

\subsection{Reliability and Validity Tests}

AMOS 21.0 software was used to conduct confirmatory factor analysis (CFA) with maximum likelihood to evaluate the model construction and construct validity. The results are summarized in Table 1. The overall model's goodness of fit of the CFA was above the recommended level: $\chi^{2} / d f=1.744$ $(1<,<3), \mathrm{RMSRA}=0.043(<0.05), \mathrm{RMR}=0.079(<0.08), \mathrm{GFI}=0.914(>0.9), \mathrm{NFI}=0.901(>0.9)$, AGFI $=0.889(>0.8)$, IFI $=0.955(>0.9)$, TLI $=0.946(>0.9)$, CFI $=0.955(>0.9)$, PGFI $=0.713(>0.5)$, indicating that the model fitted well with valid data. Additionally, the Cronbach's $\alpha$ for PEDI (0.827), EI (0.832), PEA (0.833), PEB (0.862), Confucian culture (0.750), behavior-identity matching (0.845), Mianzi (0.750), and listening to others (0.727) were all higher than 0.7 , indicating the questionnaire had good internal consistency. The standard factor loading coefficient of each construct was above 0.5. The average variance extracted (AVE) estimates ranged from 0.508 to 0.681 , which exceeded the cut-off value of 0.5 , and the composite reliability (CR) ranged from 0.767 to 0.895 , which surpassed the recommended 0.7 threshold. These results indicated that the questionnaire had good construct validity.

Table 1. Confirmatory factor analysis $(n=402)$.

\begin{tabular}{|c|c|c|c|c|c|c|c|}
\hline Construct & Items & $\begin{array}{c}\text { Factor } \\
\text { Loading }\end{array}$ & $\mathbf{t}$ & AVE & CR & $\begin{array}{l}\text { Cronbach's } \\
\alpha \text { Value }\end{array}$ & Goodness-Fit-Indices \\
\hline \multirow{4}{*}{$\begin{array}{l}\text { Pro-environmental } \\
\text { destination image } \\
\text { (PEDI) }\end{array}$} & PEI1 & 0.648 & 12.453 & \multirow{4}{*}{0.5485} & \multirow{4}{*}{0.8285} & \multirow{4}{*}{0.827} & \multirow{18}{*}{$\begin{array}{c}\chi^{2} / d f=1.744 \\
\text { RMSEA }=0.043 \\
\text { RMR }=0.079 \\
\text { GFI }=0.914 \\
\text { AGFI }=0.889 \\
\text { NFI }=0.901 \\
\text { IFI }=0.955 \\
\text { TLI }=0.946 \\
\text { CFI }=0.955 \\
\text { PGFI }=0.713\end{array}$} \\
\hline & PEI2 & 0.749 & 14.399 & & & & \\
\hline & PEI3 & 0.757 & 14.550 & & & & \\
\hline & PEI4 & 0.800 & - & & & & \\
\hline \multirow{5}{*}{$\begin{array}{l}\text { Environmental } \\
\text { identity (EI) }\end{array}$} & EI1 & 0.749 & - & \multirow{5}{*}{0.5143} & \multirow{5}{*}{0.8381} & \multirow{5}{*}{0.832} & \\
\hline & EI2 & 0.834 & 15.217 & & & & \\
\hline & EI3 & 0.591 & 12.322 & & & & \\
\hline & EI4 & 0.575 & 10.602 & & & & \\
\hline & EI5 & 0.797 & 13.247 & & & & \\
\hline \multirow{5}{*}{$\begin{array}{l}\text { Pro-environmental } \\
\text { attitudes (PEA) }\end{array}$} & PEA1 & 0.692 & - & \multirow{5}{*}{0.5079} & \multirow{5}{*}{0.8365} & \multirow{5}{*}{0.833} & \\
\hline & PEA2 & 0.656 & 11.706 & & & & \\
\hline & PEA3 & 0.627 & 11.233 & & & & \\
\hline & PEA4 & 0.796 & 13.811 & & & & \\
\hline & PEA5 & 0.777 & 13.558 & & & & \\
\hline \multirow{4}{*}{$\begin{array}{l}\text { Pro-environmental } \\
\text { behavior (PEB) }\end{array}$} & PEB1 & 0.876 & 15.279 & \multirow{4}{*}{0.6809} & \multirow{4}{*}{0.8949} & \multirow{4}{*}{0.862} & \\
\hline & PEB2 & 0.847 & 14.124 & & & & \\
\hline & PEB3 & 0.794 & 14.601 & & & & \\
\hline & PEB4 & 0.780 & - & & & & \\
\hline
\end{tabular}


Table 1. Cont.

\begin{tabular}{|c|c|c|c|c|c|c|c|}
\hline Construct & Items & $\begin{array}{l}\text { Factor } \\
\text { Loading }\end{array}$ & $\mathbf{t}$ & AVE & CR & $\begin{array}{c}\text { Cronbach's } \\
\alpha \text { Value }\end{array}$ & Goodness-Fit-Indices \\
\hline \multirow{3}{*}{$\begin{array}{l}\text { Behavior-identity } \\
\text { matching }\end{array}$} & BIM1 & 0.740 & - & \multirow{3}{*}{0.6491} & \multirow{3}{*}{0.8469} & \multirow{3}{*}{0.845} & \\
\hline & BIM2 & 0.846 & 15.375 & & & & \\
\hline & BIM3 & 0.827 & 15.234 & & & & \\
\hline \multirow{3}{*}{ Mianzi } & MZ1 & 0.562 & - & \multirow{3}{*}{0.5819} & \multirow{3}{*}{0.8034} & \multirow{3}{*}{0.750} & \\
\hline & MZ2 & 0.909 & 9.734 & & & & \\
\hline & MZ3 & 0.703 & 10.22 & & & & \\
\hline \multirow{3}{*}{ Listening to others } & LTO1 & 0.686 & - & \multirow{3}{*}{0.5245} & \multirow{3}{*}{0.7668} & \multirow{3}{*}{0.727} & \\
\hline & LTO2 & 0.802 & 10.791 & & & & \\
\hline & LTO3 & 0.678 & 9.956 & & & & \\
\hline
\end{tabular}

\subsection{Correlation Analysis}

As can be seen in Table 2, except for Mianzi, there were significant correlations between all of the constructs. Discriminant validity was confirmed because the square roots of the AVE of each construct were larger than the correlation of the specific factor with any other factor in the model.

Table 2. Correlations and squared roots of $\operatorname{AVE}(n=402)$.

\begin{tabular}{lccccccc}
\hline \multicolumn{1}{c}{ Construct } & $\mathbf{1}$ & $\mathbf{2}$ & $\mathbf{3}$ & $\mathbf{4}$ & $\mathbf{5}$ & $\mathbf{6}$ & $\mathbf{7}$ \\
\hline 1. Pro-environmental destination image & $(0.741)$ & & & & & & \\
2. Environmental identity & $0.271^{* *}$ & $(0.717)$ & & & & & \\
3. Pro-environmental attitudes & $0.268^{* *}$ & $0.523^{* *}$ & $(0.713)$ & & & & \\
4. Pro-environmental behavior & $0.171^{* *}$ & $0.630^{* *}$ & $0.526^{* *}$ & $(0.825)$ & & & \\
5. Behavior-identity matching & $0.101^{*}$ & $0.306^{* *}$ & $0.256^{* *}$ & $0.339^{* *}$ & $(0.806)$ & & \\
6. Mianzi & $0.172^{* *}$ & 0.027 & 0.080 & -0.079 & $0.245^{* *}$ & $(0.763)$ & \\
7. Listening to others & $0.266^{* *}$ & $0.428^{* *}$ & $0.336^{* *}$ & $0.476^{* *}$ & $0.372^{* *}$ & 0.045 & $(0.724)$ \\
\hline
\end{tabular}

Notes: 1. The diagonal element is the square root of the extracted mean variance. 2. ${ }^{* *}$ significant at $p<0.01$;

* significant at $p<0.05$.

\subsubsection{Tests of Hypotheses}

To explore the multiple relationships between PEDI and residents' PEB, structural equation modeling (SEM) with AMOS 21.0 was applied. The number of bootstrap samples was 2000 with a 95\% confidence interval (Table 3 and Figure 2). The overall model fit indices suggested that the actual data fitted well and could be used for hypothesis testing: $\chi^{2} / d f=2.047$, RMSRA $=0.051, \mathrm{RMR}=0.057$, $\mathrm{GFI}=0.932, \mathrm{NFI}=0.926, \mathrm{AGFI}=0.908, \mathrm{IFI}=0.961, \mathrm{TLI}=0.952, \mathrm{CFI}=0.961$, and $\mathrm{PGFI}=0.687$.

Table 3. Structural paths and hypotheses testing $(n=402)$.

\begin{tabular}{|c|c|c|c|c|c|c|}
\hline & \multirow[b]{2}{*}{ Path } & \multirow{2}{*}{ Effect } & \multirow{2}{*}{ S.E. } & \multicolumn{2}{|c|}{ Bias-Corrected $95 \%$ CI } & \multirow{2}{*}{$p$ Value } \\
\hline & & & & Lower & Higher & \\
\hline \multirow{6}{*}{ Direct effect } & $\mathrm{PEDI} \rightarrow \mathrm{EI}$ & 0.280 & 0.060 & 0.165 & 0.399 & 0.001 \\
\hline & $\mathrm{EI} \rightarrow \mathrm{PEA}$ & 0.558 & 0.060 & 0.435 & 0.673 & 0.001 \\
\hline & $\mathrm{PEDI} \rightarrow \mathrm{PEA}$ & 0.164 & 0.057 & 0.053 & 0.274 & 0.006 \\
\hline & $\mathrm{PEDI} \rightarrow \mathrm{PEB}$ & -0.063 & 0.053 & -0.174 & 0.035 & 0.217 \\
\hline & $\mathrm{PEA} \rightarrow \mathrm{PEB}$ & 0.330 & 0.081 & 0.165 & 0.485 & 0.001 \\
\hline & $\mathrm{EI} \rightarrow \mathrm{PEB}$ & 0.514 & 0.084 & 0.345 & 0.672 & 0.001 \\
\hline \multirow{5}{*}{ Indirect effect } & $\mathrm{PEDI} \rightarrow \mathrm{EI} \rightarrow \mathrm{PEA}$ & 0.156 & 0.038 & 0.091 & 0.241 & 0.000 \\
\hline & $\mathrm{PEDI} \rightarrow \mathrm{EI} \rightarrow \mathrm{PEB}$ & 0.197 & 0.046 & 0.114 & 0.296 & 0.001 \\
\hline & $\mathrm{PEDI} \rightarrow \mathrm{PEA} \rightarrow \mathrm{PEB}$ & 0.199 & 0.044 & 0.120 & 0.294 & 0.001 \\
\hline & $\mathrm{PEDI} \rightarrow \mathrm{EI} \rightarrow \mathrm{PEA} \rightarrow \mathrm{PEB}$ & 0.250 & 0.050 & 0.161 & 0.354 & 0.001 \\
\hline & $\mathrm{EI} \rightarrow \mathrm{PEA} \rightarrow \mathrm{PEB}$ & 0.184 & 0.047 & 0.100 & 0.285 & 0.000 \\
\hline
\end{tabular}

Notes: PEDI $=$ Pro-environmental destination image; EI $=$ Environmental identity; PEA $=$ Pro-environmental attitudes; $\mathrm{PEB}=$ pro-environmental behavior. 


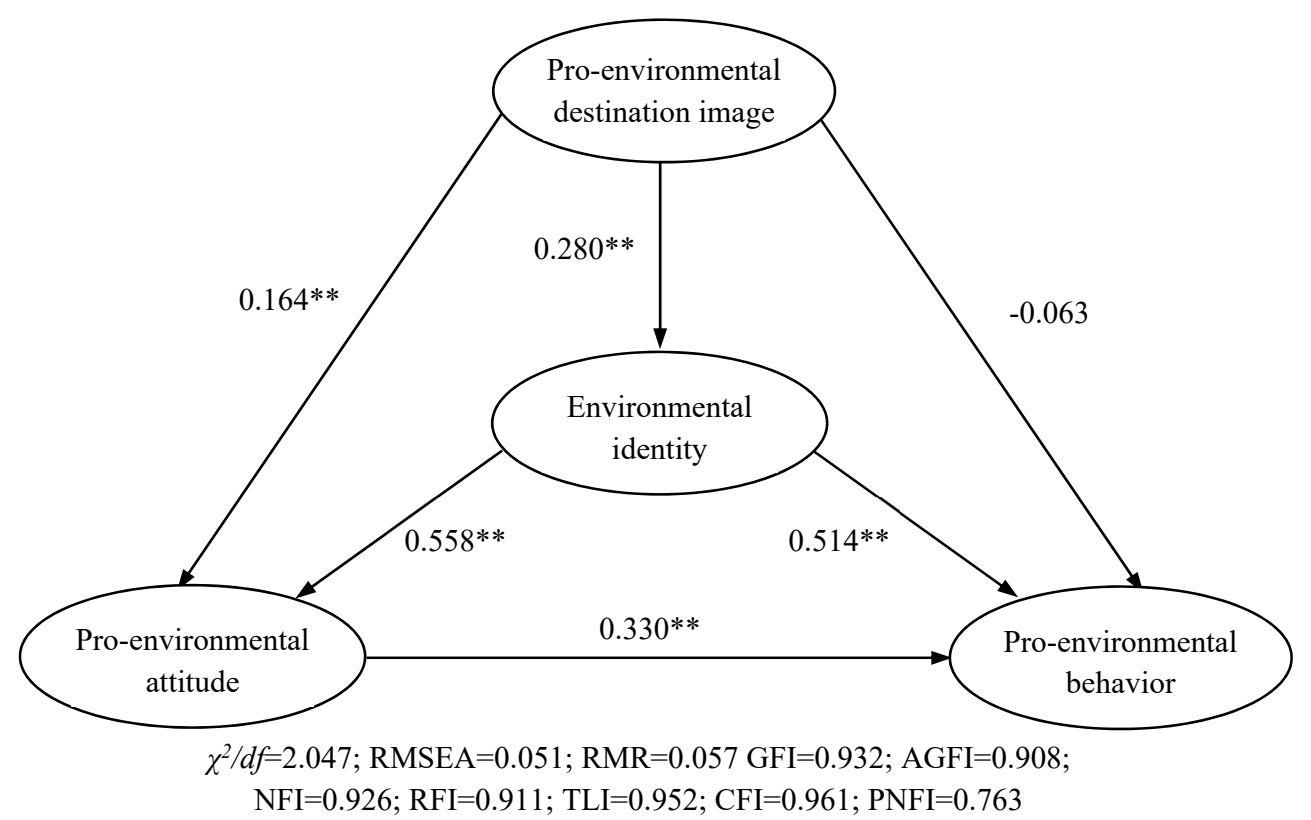

Figure 2. The estimated structural equation model; ${ }^{* *}$ significant at $p<0.01$.

\subsubsection{Direct and Mediating Effects}

To investigate the direct and mediating effects, the bias-corrected bootstrapping method was employed. The results for the direct effects showed that PEDI had a significant and positive impact on residents' environmental identity $(\beta=0.280, p=0.001$ ) and residents' pro-environmental attitudes ( $\beta=0.164, p=0.006)$, which supported H1a and H1b.

The results for the indirect effect also showed that residents' environmental identity significantly mediated the effect of PEDI on residents' PEB. Specifically, the direct effect of PEDI on PEB was not significant, which demonstrates that environmental identity completely mediated the relationship between PEDI and PEB (PEDI $\rightarrow$ EI $\rightarrow$ PEB; 0.197, $p=0.001,95 \%$ bootstrap confidence interval [CI] $=0.114-0.296$ ) (Table 3). Similarly, residents' pro-environmental attitudes completely mediated the relationship between PEDI and PEB (PEDI $\rightarrow$ PEA $\rightarrow$ PEB; $0.199, p=0.001, \mathrm{CI}=0.120-0.294$ ). Additionally, both environmental identity and pro-environmental attitudes completely mediated the relationship between PEDI and PEB (PEDI $\rightarrow$ EI $\rightarrow$ PEA $\rightarrow$ PEB; 0.250, $p=0.000,[\mathrm{CI}]=0.161-0.354$ ). Therefore, H2a and $\mathrm{H} 2 \mathrm{~b}$ were also supported.

By comparing the direct, indirect, and total effect results concerning the relationship between PEDI and PEB, it was found that PEDI affected PEB through the complete mediation of environmental identity and pro-environmental attitudes. For this reason, H1c was also supported.

\subsubsection{Moderating Effect}

To confirm the moderating effect of Confucian culture, hierarchical regression provided by SPSS 21.0 was performed to test the following models:

$$
\begin{aligned}
\mathrm{EI}_{\mathrm{i}}=\alpha_{0}+\alpha_{1} \times \mathrm{PEDI}+\alpha_{2} \times \mathrm{CC}+\alpha_{3} \times \mathrm{PEDI} \times \mathrm{CC}+\alpha_{4} \times \mathrm{CC}^{2}+\alpha_{5} \times \mathrm{PEDI} \times \mathrm{CC}^{2}+\alpha_{6} \times \\
\text { GENDER }+\alpha_{7} \times \mathrm{AGE}+\alpha_{8} \times \mathrm{EDUCATION}+\alpha_{9} \times \mathrm{INCOME}+\delta_{\mathrm{i}} \\
\mathrm{PEA}_{\mathrm{i}}=\beta_{0}+\beta_{1} \times \mathrm{PEDI}+\beta_{2} \times \mathrm{CC}+\beta_{3} \times \mathrm{PEDI} \times \mathrm{CC}+\beta_{4} \times \mathrm{CC}^{2}+\beta_{5} \times \mathrm{PEDI} \times \mathrm{CC}^{2}+\beta_{6} \times \\
\text { GENDER }+\beta_{7} \times \mathrm{AGE}+\beta_{8} \times \mathrm{EDUCATION}+\beta_{9} \times \mathrm{INCOME}+\xi_{\mathrm{i}} \\
\mathrm{PEB}_{\mathrm{i}}=\gamma_{0}+\gamma_{1} \times \mathrm{PEDI}+\gamma_{2} \times \mathrm{CC}+\gamma_{3} \times \mathrm{PEDI} \times \mathrm{CC}+\gamma_{4} \times \mathrm{CC}^{2}+\gamma_{5} \times \mathrm{PEDI} \times \mathrm{CC}^{2}+\gamma_{6} \times \\
\text { GENDER }+\gamma_{7} \times \mathrm{AGE}+\gamma_{8} \times \mathrm{EDUCATION}+\gamma_{9} \times \mathrm{INCOME}+\gamma_{\mathrm{i} .} .
\end{aligned}
$$

Among them, $\alpha_{0}, \beta_{0}$, and $\gamma_{0}$ were constants, while $\delta_{i}, \xi_{i}$, and $v_{i}$ were disturbances of the model. 
The dependent variable in model (1) was residents' environmental identity and the results are summarized in Table 4. First, the control variables including gender, age, education, and income were included in model a1. Second, on the basis of model a1, PEDI, CC, and $C^{2}{ }^{2}$ were included in model a2. The results showed that PEDI had a significant and positive impact on residents' environmental identity $(\beta=0.187, t=3.883)$, which supported H1a again. Third, the interaction variables, PEDI $\times C C$ and PEDI $\times \mathrm{CC}^{2}$, were included in model a3 on the basis of model a2. The results showed that the coefficient of the interaction term, PEDI $\times C C$, had a significant and negative impact on residents' environmental identity $\left(\beta=-0.125^{*}, t=-2.427\right)$, and the coefficient of the interaction term, PEDI $\times C^{2}$, had a significant and positive impact on residents' environmental identity $\left(\beta=0.138^{*}, \mathrm{t}=2.159\right)$, which confirmed that Confucian culture had a positive U-shaped moderating effect in the relationship between PEDI and environmental identity, and supported H3a.

Table 4. Moderating effects of Confucian culture (CC) on the relationship between PEDI and EI.

\begin{tabular}{|c|c|c|c|c|c|c|c|}
\hline \multirow{3}{*}{ Variable } & \multicolumn{7}{|c|}{ Dependent Variable: Environmental Identity (EI) } \\
\hline & \multirow[t]{2}{*}{$n=402$} & \multicolumn{2}{|c|}{ Model a1 } & \multicolumn{2}{|c|}{ Model a2 } & \multicolumn{2}{|c|}{ Model a3 } \\
\hline & & $\beta$ & $\mathbf{t}$ & $\beta$ & $\mathbf{t}$ & $\beta$ & $\mathbf{t}$ \\
\hline \multirow{4}{*}{ Control variable } & Gender & -0.04 & -0.805 & -0.002 & -0.048 & -0.001 & -0.028 \\
\hline & Age & $0.116^{*}$ & 1.981 & 0.076 & 1.382 & 0.082 & 1.509 \\
\hline & Education & -0.047 & -0.942 & -0.002 & -0.043 & 0.003 & 0.058 \\
\hline & Income & 0.010 & 0.163 & -0.003 & -0.047 & 0.001 & 0.02 \\
\hline \multirow{3}{*}{ Independent variable } & PEDI & & & $0.187^{* * *}$ & 3.883 & $0.114 *$ & 2.079 \\
\hline & $\mathrm{CC}$ & & & $0.288^{* * *}$ & 5.987 & $0.252 * * *$ & 5.028 \\
\hline & $C C^{2}$ & & & -0.049 & -1.052 & 0.053 & 0.98 \\
\hline \multirow{2}{*}{ Interaction variable } & PEDI $\times$ CC & & & & & $-0.125 *$ & -2.427 \\
\hline & $\mathrm{PEDI} \times \mathrm{CC}^{2}$ & & & & & $0.138 *$ & 2.159 \\
\hline $\mathrm{R}^{2}$ & & \multicolumn{2}{|c|}{0.020} & \multicolumn{2}{|c|}{0.165} & \multicolumn{2}{|c|}{0.191} \\
\hline Adj- $R^{2}$ & & \multicolumn{2}{|c|}{0.010} & \multicolumn{2}{|c|}{0.150} & \multicolumn{2}{|c|}{0.173} \\
\hline
\end{tabular}

Notes: ${ }^{*}$ significant at $p<0.05 ;{ }^{* *}$ significant at $p<0.01 ;{ }^{* * *}$ significant at $p<0.001$.

The dependent variable in model (2) was residents' pro-environmental attitudes, and the results are summarized in Table 5. First, the control variables including gender, age, education, and income were included in model b1. Second, on the basis of model b1, PEDI, CC, and $C^{2}$ were included in model b2. The results showed that PEDI had a significant and positive impact on residents' pro-environmental attitudes $(\beta=0.190, t=3.900)$, which again supported $\mathrm{H} 1 \mathrm{~b}$. Lastly, the interaction variables, PEDI $\times C C$ and PEDI $\times C^{2}$, were included in model $b 3$ on the basis of model b2. The results showed that the coefficient of the interaction term, PEDI $\times$ CC, had no significant impact on residents' pro-environmental attitudes $(\beta=-0.052, t=-0.999)$, and the coefficient of the interaction term, PEDI $\times C C^{2}$, had a significant and positive impact on residents' pro-environmental attitudes $(\beta=0.150 *, \mathrm{t}$ $=2.296$ ), which confirmed that Confucian culture had a positive U-shaped moderating effect in the relationship between PEDI and pro-environmental attitudes, and supported H3b. 
Table 5. Moderating effects of CC on the relationship between PEDI and PEA.

\begin{tabular}{|c|c|c|c|c|c|c|c|}
\hline \multirow{3}{*}{ Variable } & \multicolumn{7}{|c|}{ Dependent Variable: Pro-Environmental Environmental Attitudes (PEA) } \\
\hline & \multirow[t]{2}{*}{$n=402$} & \multicolumn{2}{|c|}{ Model b1 } & \multicolumn{2}{|c|}{ Model b2 } & \multicolumn{2}{|c|}{ Model b3 } \\
\hline & & $\beta$ & $\mathbf{t}$ & $\beta$ & $\mathbf{t}$ & $\beta$ & $\mathbf{t}$ \\
\hline \multirow{4}{*}{ Control Variable } & Gender & 0.005 & 0.093 & 0.04 & 0.857 & 0.041 & 0.88 \\
\hline & Age & 0.078 & 1.324 & 0.041 & 0.739 & 0.043 & 0.778 \\
\hline & Education & $-0.109 *$ & -2.177 & -0.067 & -1.413 & -0.061 & -1.289 \\
\hline & Income & 0.033 & 0.561 & 0.021 & 0.385 & 0.023 & 0.428 \\
\hline \multirow{3}{*}{ Independent variable } & PEDI & & & $0.190^{* * *}$ & 3.900 & $0.119 *$ & 2.132 \\
\hline & $\mathrm{CC}$ & & & $0.248^{* * *}$ & 5.109 & $0.210^{* * *}$ & 4.132 \\
\hline & $C C^{2}$ & & & -0.062 & -1.32 & 0.014 & 0.252 \\
\hline \multirow{2}{*}{ Interaction } & PEDI $\times$ CC & & & & & -0.052 & -0.999 \\
\hline & $\mathrm{PEDI} \times \mathrm{CC}^{2}$ & & & & & 0.150 * & 2.296 \\
\hline $\mathrm{R}^{2}$ & & \multicolumn{2}{|c|}{0.023} & \multicolumn{2}{|c|}{0.148} & \multicolumn{2}{|c|}{0.163} \\
\hline Adj- $R^{2}$ & & \multicolumn{2}{|c|}{0.014} & \multicolumn{2}{|c|}{0.133} & \multicolumn{2}{|c|}{0.144} \\
\hline
\end{tabular}

The dependent variable in model (3) was residents' PEB, and the results are summarized in Table 6. First, the control variables including gender, age, education, and income were included in model $\mathrm{c}$. Second, on the basis of model c1, PEDI, CC, and $C^{2}{ }^{2}$ were included in model $\mathrm{c} 2$. The results showed that PEDI had no significant impact on residents' PEB $(\beta=0.089, t=1.799)$. Third, the interaction variables, PEDI $\times$ CC and PEDI $\times \mathrm{CC}^{2}$, were included in model $\mathrm{c} 3$ on the basis of model $\mathrm{c} 2$. The results showed that the coefficient of the interaction term, PEDI $\times C C$, had a significant and negative impact on residents' PEB $(\beta=-0.128 * t=-2.441)$, and the coefficient of the interaction term, PEDI $\times \mathrm{CC}^{2}$, had a significant and positive impact on residents' PEB $\left(\beta=0.131^{*}, t=2.009\right)$, which confirmed that Confucian culture had a positive U-shaped moderating effect in the relationship between PEDI and $\mathrm{PEB}$, and supported H3c. In addition, the variance inflation factors (VIFs) of all regression models were between 1.012 and 1.989, indicating that multicollinearity was not a major concern in this research.

Table 6. Moderating effects of CC on the relationship between PEDI and PEB.

\begin{tabular}{|c|c|c|c|c|c|c|c|}
\hline \multirow{3}{*}{ Variable } & \multicolumn{7}{|c|}{ Dependent Variable: Pro-Environmental Behavior (PEB) } \\
\hline & \multirow[t]{2}{*}{$n=402$} & \multicolumn{2}{|c|}{ Model c1 } & \multicolumn{2}{|c|}{ Model c2 } & \multicolumn{2}{|c|}{ Model c3 } \\
\hline & & $\beta$ & $\mathbf{T}$ & $\beta$ & $\mathbf{t}$ & $\beta$ & t \\
\hline \multirow{4}{*}{ Control variable } & Gender & 0.047 & 0.94 & 0.077 & 1.622 & 0.078 & 1.662 \\
\hline & Age & 0.091 & 1.544 & 0.057 & 1.014 & 0.063 & 1.137 \\
\hline & Education & -0.081 & -1.616 & -0.047 & -0.985 & -0.043 & -0.904 \\
\hline & Income & -0.019 & -0.315 & -0.029 & -0.528 & -0.026 & -0.468 \\
\hline \multirow{3}{*}{ Independent variable } & PEDI & & & 0.089 & 1.799 & 0.018 & 0.327 \\
\hline & $\mathrm{CC}$ & & & $0.304 *$ & 6.197 & 0.270 * & 5.272 \\
\hline & $\mathrm{CC}^{2}$ & & & -0.033 & -0.695 & 0.068 & 1.228 \\
\hline \multirow{2}{*}{ Interaction } & PEDI $\times$ CC & & & & & $-0.128 *$ & -2.441 \\
\hline & $\mathrm{PEDI} \times \mathrm{CC}^{2}$ & & & & & 0.131 * & 2.009 \\
\hline $\mathrm{R}^{2}$ & & \multicolumn{2}{|c|}{0.017} & \multicolumn{2}{|c|}{0.130} & \multicolumn{2}{|c|}{0.156} \\
\hline Adj- $R^{2}$ & & \multicolumn{2}{|c|}{0.007} & \multicolumn{2}{|c|}{0.115} & \multicolumn{2}{|c|}{0.137} \\
\hline
\end{tabular}




\section{Conclusions and Implications}

\subsection{Conclusions}

With the rapid development of tourism, the negative impacts on the environment have become increasingly prominent. Therefore, it is becoming more necessary to identify the factors that influence destination residents' environmental behavior. This research explored the contextual and cultural factors that influence residents' PEB from the behavioral setting perspective and produced several key findings.

First, the results revealed that residents' environmental identity and pro-environmental attitudes have a significant and positive impact on PEB. When the levels of residents' environmental identity and pro-environmental attitudes are stronger, their tendency to engage in PEB is greater, which is consistent with the findings of Guagnano et al. [19], Stets and Biga [12], Shin et al. [59], and Casaló and Escario [63]. In addition, the impact of residents' environmental identity was stronger than the impact of pro-environmental attitudes, and their identity influenced environmental behavior through the partial mediation of pro-environmental attitudes, which indicated the supporting role of pro-environmental attitudes in this relationship.

Second, this research identified the leading role of PEDI in predicting residents' PEB and uncovered the mediating role of environmental identity and pro-environmental attitudes in the influence of PEDI. Specifically, PEDI had a significant and positive impact on residents' environmental identity, pro-environmental attitudes, and PEB. The findings are consistent with the theory of social information processing [39]. For example, the pro-environmental setting and perceived situation provided by a destination encourages residents to adjust their environmental understanding, attitudes, and behavior and to adapt to the destination's environment. The results also showed that environmental identity and pro-environmental attitudes played multiple mediating roles in the relationship between PEDI and residents' PEB. Accordingly, this research identified the mediating role of environmental identity and pro-environmental attitudes in pro-environmental contexts. That is, when residents' perception of PEDI was more positive, their level of engagement in PEB through their environmental identity and pro-environmental attitudes was higher.

Third, this research showed that Confucian culture had a positive U-shaped moderating effect in the relationship among PEDI, environmental identity, pro-environmental attitudes, and PEB. That is, with an increase in residents' recognition of and adherence to Confucian culture, the positive effect of PEDI on environmental identity, pro-environmental attitudes, and PEB decreased first and then increased. When residents had minimal recognition of and adherence to Confucian culture, such as low behavior-identity matching, less concern for Mianzi and the opinions of others, their attitudes and behavior related to the environment were relatively free and unrestricted. Additionally, the pro-environmental images created by protected areas and DMOs encouraged these people to believe that environmental conditions were acceptable, which may have weakened their perceptions of the potential contributions of their PEBs and fostered the belief that maintaining the environment was the responsibility of the protected areas and DMOs. Thus, they had lower PEBs and Confucian culture exerted a negative moderating effect at low levels and reduced these residents' identity, attitudes, and behavior related to the environment. As residents' recognition of and adherence to Confucian culture increased, this motivated people to pay greater attention to and absorb eco-friendly information. When residents had high recognition of and adherence to Confucian culture, they were more susceptible to the influence of people and their environmental surroundings, and consequently demonstrated higher levels of PEB. Here, Confucian culture had a positive moderating effect at high levels and increased residents' identity, attitudes, and behavior related to the environment. This is consistent with the findings of Wang et al. [24], Xu et al. [51], and Yao [52]. 


\subsection{Theoretical Implications}

The findings have several theoretical implications. First, this investigation focused on the effect of PEDI on residents' PEB and contributed to the literature by extending the predictive factors and research context for environmental behavior. The attitude-context-behavior theory proposed by Guagnano et al. [19] is widely recognized and Stets and Biga [13] explored the relationship among environmental identity, attitudes, and behaviors with university students as the target group. Based on that work, the current research examined the influence of PEDI as a key variable and proposed an integrated model of PEDI, environmental identity, pro-environmental attitudes, and PEB with residents as the target group. The findings confirmed that residents' PEB was influenced by both internal attitudinal and external contextual factors and identified the inductive effect of contextual factors (pro-environmental setting) on the relationship between environmental attitudes and behavior. In addition, the multiple mediating effect of environmental identity and pro-environmental attitudes in motivating residents to form PEB in the context of a pro-environmental image, extends the research of Lee and Jeong [30]. Therefore, the theoretical contribution is to expand the attitude-context-behavior theory in the pro-environmental context and extend knowledge on the predictive factors of residents' environmental behavior from the interactive perspective of the environment and behavior.

Second, this research identified the positive U-shaped moderating effect of Confucianism in the context of Chinese traditional culture and emphasized its role in motivating residents' PEB. Previous studies have focused on the influence of Confucian culture on environmental awareness and attitudes, as well as its effect on customers' green purchase intentions [24] and the uncivilized behavior of Chinese tourists [64]. However, the formation of resident' environmental behavior under Confucianism has been less well researched, as well as the positive U-shaped moderating effect of Confucian culture. The findings are particularly important for fostering residents' environmental behavior because they not only enrich the research on the positive moderation effect of Confucian culture on environmental behavior in a PEB setting when residents have a high adherence, but also reveal the negative moderation effect of Confucian culture in motivating environmental behavior when residents have low adherence. Therefore, a theoretical contribution of this research is to expand residents' PEB in the context of Chinese traditional culture.

Third, this research revealed more detail on residents' PEBs by introducing the two factors of PEDI and Confucian culture. Previous studies on environmental behavior have focused on multiple theoretical perspectives and environmental attitudes have been identified as a key factor in the prediction of environmental behavior. The environmental "identity-attitude-behavior" research framework was used to predict environmental behavior [13]. However, the combined influence of pro-environmental image and foundational cultural factors on PEB has not been sufficiently explored. This research used PEDI and Confucian culture as contextual and cultural factors, respectively, and constructed a comprehensive model to predict resident' PEB based on the environmental "identity-attitude-behavior" research framework. This research could expand the literature on the promotion of residents' PEB and provides a new theoretical perspective and research direction in this field.

\subsection{Managerial Implications}

There are several practical implications for agencies responsible for developing and marketing tourism, as well as those in resource protection and conservation. First, these organizations need to create and cultivate a PEB setting and atmosphere for residents and motivate them to actively engage in PEBs by publicizing eco-friendly image elements. A pro-environmental destination image can be an important contextual factor that drives residents' PEB when residents perceive a low contribution provided by their behavior. Therefore, DMOs and protected areas should strategically emphasize the design and cultivation of pro-environmental image and create pro-environmental physical spaces for destinations through measures such as green coverage, resource recycling, ecological promotion and publicity, and environmental signs, thereby improving the environmental quality of destinations. The creation of pro-environmental images and behavioral settings for destinations requires input from 
multiple participants, including residents, tourism practitioners, managers, and tourists. Additionally, DMOs and protected areas should encourage residents and other stakeholders to participate in the cultivation of pro-environmental images and atmosphere and ultimately promote sustainable destination development by creating eco-friendly social spaces and social atmospheres.

Second, the findings provide DMOs and protected areas with insights into the supportive role of environmental identity and pro-environmental attitudes in motivating PEBs. DMOs and protected areas should emphasize the creation of PEB settings, as well as environmental image communication and environmental awareness education to ensure that residents can clearly understand and identify the pro-environmental elements of destinations. In this way, residents can develop a higher level of environmental identity and pro-environmental attitudes through the organization, absorption, and transformation of pro-environmental elements, which improves residents' PEB.

Third, useful guidance is provided regarding Confucian culture, and how it facilitates residents' environmental identity and pro-environmental attitudes and contributes to residents' PEB. Due to the positive U-shaped moderating effect of Confucian culture, it is especially important for tourism organizations to integrate this culture within brand development and environmental education. Confucianism should also be embedded within the settings of destinations. For example, residents should be recognized and rewarded for environmental friendliness. Additionally, resident behavior that harms the environment should be highlighted along with the loss of personal Mianzi and community reputation. An atmosphere of mutual restraint can be achieved by developing large-scale environmental education initiatives, as well as by encouraging residents to listen to one another.

\subsection{Research Limitations and Future Studies}

Some limitations of this research need to be acknowledged. First, the method was limited to a cross-sectional survey and samples of Chinese residents from Xiamen, Quanzhou, and Guiyang. Future research could employ different designs such as using the experimental method to test the conceptual model. Second, this analysis was limited to studying the moderating effect of traditional Confucian culture. Although this is the traditional culture that has the deepest impact on the Chinese, the influence of Taoism and Buddhism is also deeply rooted. Additionally, Chinese values are constantly changing with the development of the economy and information technology. Future research should incorporate these factors to explore the impact of Confucian culture and to extend the generalizability of these results.

It also must be mentioned that many parts of China are experiencing rapid tourism development $[65,66]$ and this is increasing the pressure on destination environments. Previous authors have acknowledged that government institutions are the main driving force spurring tourism development in China rather than the private sector or residents [65] and that socially and environmentally sustainable tourism development was not receiving enough attention [65]. Therefore, there is still a need in China for greater resident involvement in tourism development and to take heed of their pro-environmental concerns and suggestions.

Author Contributions: J.Z. contributed to the conceptualizing, designing, collecting, and analyzing the questionnaire; C.X. and A.M.M. made substantial contribution to the paper design, questionnaire design, and critical revisions to the work of J.Z. K.Z. contributed in data collection and data analysis. All authors have read and agreed to the published version of the manuscript.

Funding: This research was financially supported by the National Natural Science Foundation of China (Grant No. 41971182) and Humanities and Social Sciences Science Foundation of Ministry of Education of China (Grant No. 19YJAZH097).

Conflicts of Interest: The authors declare no conflict of interest.

\section{References}

1. Nunkoo, R.; Ramkissoon, H. Residents' satisfaction with community attributes and support for tourism. J. Hosp. Tour. Res. 2010, 35, 171-190. [CrossRef] 
2. Nunkoo, R.; Ramkissoon, H. Developing a community support model for tourism. Ann. Tour. Res. 2011, 38, 964-988. [CrossRef]

3. Andereck, K.L.; Nyaupane, G.P. Exploring the nature of tourism and quality of life perceptions among residents. J. Travel Res. 2011, 50, 248-260. [CrossRef]

4. Groizard José, L.; Santana-Gallego, M. The destruction of cultural heritage and international tourism: The case of the Arab countries. J. Cult. Herit. 2018, 33, 285-292. [CrossRef]

5. Zhang, Y.L.; Zhang, J.; Ye, Y.Y.; Wu, Q.T.; Jin, L.X.; Zhang, H.G. Residents' Environmental Conservation Behaviors at Tourist Sites: Broadening the Norm Activation Framework by Adopting Environment Attachment. Sustainability 2016, 8, 571. [CrossRef]

6. Bamberg, S.; Mser, G. Twenty years after Hines, Hungerford, and Tomera: A new meta-analysis of psycho-social determinants of pro-environmental behavior. J. Environ. Psychol. 2007, 27, 14-25. [CrossRef]

7. Han, H. Travelers' pro-environmental behavior in a green lodging context: Converging value-belief-norm theory and the theory of planned behavior. Tour. Manag. 2015, 47, 164-177. [CrossRef]

8. Wang, C.; Zhang, J.; Yu, P.; Hu, H. The theory of planned behavior as a model for understanding tourists' responsible environmental behaviors: The moderating role of environmental interpretations. J. Clean. Prod. 2018, 194, 425-434. [CrossRef]

9. Chen, W.; Cao, C.; Fang, X.; Kang, Z. Expanding the Theory of Planned Behavior to Reveal Urban Residents' Pro-Environment Travel Behavior. Atmosphere 2019, 10, 467. [CrossRef]

10. Vaske, J.J.; Kobrin, K.C. Place attachment and environmentally responsible behavior. J. Environ. Educ. 2001, 32, 16-21. [CrossRef]

11. Schultz, P.W. The structure of environmental concern: Concern for self, other people and the biosphere. J. Environ. Psychol. 2001, 21, 327-339. [CrossRef]

12. Milfont, T.L.; Duckitt, J. The environmental attitudes inventory: A valid and reliable measure to assess the structure of environmental attitudes. J. Environ. Psychol. 2010, 30, 80-94. [CrossRef]

13. Stets, J.E.; Biga, C.F. Bringing identity theory into environmental sociology. Sociol. Theory 2003, 21, 398-423. [CrossRef]

14. Nunkoo, R.; Gursoy, D. Residents' support for tourism: An identity perspective. Ann. Tour. Res. 2012, 39, 243-268. [CrossRef]

15. Li, Q.; Zhou, L. The impact of social capital on tourists' intention to exhibit environment-friendly behaviors. Tour. Trib. 2014, 29, 73-82.

16. Zhang, H.-Z.; Li, Q.-C.; Wu, M.-Y. Exploring the driving mechanism of tourists 'intention for ecological behaviors in natural destinations: Empirical evidence from Zhangjiajie and Xixi wetland. Econ. Geogr. 2016, 36, 204-210.

17. Ostrom, E. Governing the Commons: The Evolution of Institutions for Collective Action; Cambridge University Press: New York, NY, USA, 1990.

18. Steg, L.; Groot, J.D. Explaining prosocial intentions: Testing causal relationships in the norm activation model. Br. J. Soc. Psychol. 2009, 49 Pt 4, 725-743. [CrossRef]

19. Guagnano, G.A.; Stern, P.C.; Dietz, T. Influences on Attitude-Behavior Relationships: A Natural Experiment with Curbside Recycling. Environ. Behav. 1995, 27, 699-718. [CrossRef]

20. Lin, Y.; Hu, Z. Environmental Psychology; China Building Industry Press: Beijing, China, 2006; pp. 79-104.

21. Yu, X.; Wu, X.; Zhang, Y.; Wang, Y. Factors driving environmentally responsible behaviors by tourists: A case study of Taiwan, China. Tour. Trib. 2015, 30, 49-59.

22. Kacen, J.J.; Lee, J.A. The Influence of Culture on Consumer Impulsive Buying Behavior. J. Consum. Psychol. 2002, 12, 163-176. [CrossRef]

23. Wang, J.; Wang, C.; Wu, L. Mechanism of Green Emotional Appeals Impacting on the Green Purchase Decision-making Process. J. Manag. Sci. 2017, 30, 38-56.

24. Wang, J.; Bao, J.; Wang, C.; Wu, L. The impact of different emotional appeals on the purchase intention for green products: The moderating effects of green involvement and Confucian cultures. Sustain. Cities Soc. 2017, 34, 32-42. [CrossRef]

25. Lee, C. Modifying an American Consumer Behavior Model for Consumers in Confucian Culture. J. Int. Consum. Mark. 1991, 3, 27-50. [CrossRef] 
26. Zhang, S.-N.; Li, Y.-Q.; Liu, C.-H.; Ruan, W.-Q. Critical factors in the identification of word-of-mouth enhanced with travel apps: The moderating roles of Confucian culture and the switching cost view. Asia Pac. J. Tour. Res. 2019, 24, 422-442. [CrossRef]

27. Kwek, A.; Lee, Y.S. Chinese Tourists and Confucianism. Asia Pac. J. Tour. Res. 2010, 15, 129-141. [CrossRef]

28. Barich, H.; Kotler, P. A framework for marketing image management. MIT Sloan Manag. Rev. 1991, 32, 94-104.

29. Dichter, E. What's in an image. J. Consum. Mark. 1985, 2, 75-81. [CrossRef]

30. Lee, W.; Jeong, C. Effects of pro-environmental destination image and leisure sports mania on motivation and pro-environmental behavior of visitors to Korea's national parks. J. Destin. Mark. Manag. 2018, 10, 25-35. [CrossRef]

31. Park, J.Y. The effect of environmental marketing image strategy on consumer decision-making in foodservice industry: Focused on environment-friendly image. Int. J. Tour. Hosp. Res. 2010, 24, 67-83.

32. Rodrigues, A.I. Green Destination Image as a Promotional Tool for Developing Water-Based Destinations: Some Insights. In Proceedings of the I International Forum on Tourism and Heritage 2016: Water, Heritage and Sustainable Tourism, Porto, Portugal, 5-7 December 2016.

33. Jalilvand, M.R.; Samiei, N.; Dini, B.; Manzari, P.Y. Examining the structural relationships of electronic word of mouth, destination image, tourist attitude toward destination and travel intention: An integrated approach. J. Destin. Mark. Manag. 2012, 1, 134-143. [CrossRef]

34. Kani, Y.; Aziz, Y.A.; Sambasivan, M.; Bojei, J. Antecedents and outcomes of destination image of Malaysia. J. Hosp. Tour. Manag. 2017, 32, 89-98. [CrossRef]

35. Li, M.; Cai, L.A.; Lehto, X.Y.; Huang, J. A missing link in understanding revisit intention-the role of motivation and image. J. Travel Tour. Mark. 2010, 27, 335-348. [CrossRef]

36. Breakwell, G.M. Coping with Threatened Identities; Methuen: London, UK, 2015.

37. Weigert, A.J. Self, Interaction and the Natural Environment: Refocusing Our Eyesight; SUNY Press: New York, NY, USA, 1997.

38. Lu, X.-F.; Lu, L. Residents' environmental identity and support for tourism development of peripheral areas: A case study of Lugu lake scenic spot. Sci. Geogr. Sin. 2015, 35, 1404-1411.

39. Salancik, G.R.; Pfeffer, J. A social information processing approach to job attitudes and task design. Adm. Sci. Q. 1978, 23, 224-253. [CrossRef] [PubMed]

40. Eagly, A.H.; Chaiken, S. The Psychology of Attitudes; Harcourt Brace Jovanovich College Publishers: San Diego, CA, USA, 1993.

41. Steg, L.; Vlek, C. Encouraging pro-environmental behavior: An integrative review and research agenda. J. Environ. Psychol. 2009, 29, 309-317. [CrossRef]

42. Sivek, D.J.; Hungerford, H. Predictors of responsible behavior in members of three Wisconsin conservation organizations. J. Environ. Educ. 1990, 21, 35-40. [CrossRef]

43. Kahneman, D.; Tversky, A. Choices, values, and frames. Am. Psychol. 1984, 39, 341-350. [CrossRef]

44. Dogan, E.; Bolderdijk, J.W.; Steg, L. Making small numbers count: Environmental and financial feedback in promoting eco-driving behaviors. J. Consum. Policy 2014, 37, 413-422. [CrossRef]

45. Zhang, Y.; Zhang, H.L.; Zhang, J.; Cheng, S. Predicting residents' pro-environmental behaviors at tourist sites: The role of awareness of disaster's consequences, values, and place attachment. J. Environ. Psychol. 2014, 40, 131-146. [CrossRef]

46. Lee, Y.K.; Young, S.K.; Son, M.H.; Lee, D.J. Do emotions play a mediating role in the relationship between owner leadership styles and manager customer orientation, and performance in service environment? Int. J. Hosp. Manag. 2011, 30, 942-952. [CrossRef]

47. Slama, M.E.; Tashchian, A. Selected Socioeconomic and Demographic Characteristics Associated with Purchasing Involvement. J. Mark. 1985, 49, 72-82. [CrossRef]

48. Su, L.; Swanson, S.R. The effect of destination social responsibility on tourist environmentally responsible behavior: Compared analysis of first-time and repeat tourists. Tour. Manag. 2017, 60, 308-321. [CrossRef]

49. Back, K.J.; Lee, J.S. Country club members' perceptions of value, image congruence, and switching costs: An exploratory study of country club members' loyalty. J. Hosp. Tour. Res. 2009, 33, 528-546. [CrossRef]

50. Chiu, R.K. Ethical judgement, locus of control, and whistleblowing intention: A case study of mainland Chinese MBA students. Manag. Audit. J. 2002, 17, 581-587. [CrossRef] 
51. Xu, H.; Cui, Q.; Sofield, T.; Li, F.M.S. Attaining harmony: Understanding the relationship between ecotourism and protected areas in China. J. Sustain. Tour. 2014, 22, 1131-1150. [CrossRef]

52. Yao, G. Study on Chinese Resident Environmental Behavior Affected by Confucian Values and Individual Responsibility-with the Reference of the Datum for Residents Sample in Beijing. Ph.D. Thesis, Beijing Institute of Technology, Beijing, China, 2014.

53. Mintz, K.K.; Henn, L.; Park, J.; Kurman, J. What predicts household waste management behaviors? Culture and type of behavior as moderators. Resour. Conserv. Recycl. 2019, 145, 11-18. [CrossRef]

54. Zhang, M.X. Cultural Values Based on Confucianism and Symbolic Purchase Behavior: Conceptual Refinement, Measurement, Model and Marketing Strategic Suggestions. China Ind. Econ. 2005, 3, 106-112.

55. Pan, Y.; Gao, L.; Wang, F.H. Chinese Consumer Purchasing Behavior Research: From the Perspective of Confucian Culture and Lifestyle. China Ind. Econ. 2009, 9, 77-86.

56. Contrada, R.J.; Ashmore, R.D.; Gary, M.L.; Coups, E.; Egeth, J.D.; Sewell, A.; Eweel, K.; Goyal, T.M.; Chasse, V. Measures of ethnicity-related stress: Psychometric properties, ethnic group differences, and associations with well-being. J. Appl. Soc. Psychol. 2001, 31, 1775-1820. [CrossRef]

57. Stover, L.E. The Cultural Ecology of Chinese Civilization: Peasants and Elites in the Last of the Agrarian States; Pica Press: New York, NY, USA, 1974; Volume 204, pp. 231-235.

58. Brislin, R.W. Back-Translation for Cross-Cultural Research. J. Cross-Cult. Psychol. 1970, 1, 185-216. [CrossRef]

59. Shin, Y.H.; Moon, H.; Jung, S.; Severt, K. The effect of environmental values and attitudes on consumer willingness to pay more for organic menus: A value-attitude-behavior approach. J. Hosp. Tour. Manag. 2017, 33, 113-121. [CrossRef]

60. Ramkissoon, H.; Smith, L.; Weiler, B. Testing the dimensionality of place attachment and its relationships with place satisfaction and pro-environmental behaviors: A structural equation modelling approach. Tour. Manag. 2013, 36, 552-566. [CrossRef]

61. Wenjuanxing. Available online: http://www.wjx.cn (accessed on 10 January 2020).

62. Podsakoff, P.M.; Mackenzie, S.B.; Lee, J.Y.; Podsakoff, N.P. Common method biases in behavioral research: A critical review of the literature and recommended remedies. J. Appl. Psychol. 2003, 88, 879-903. [CrossRef] [PubMed]

63. Casaló, L.V.; Escario, J.J. Heterogeneity in the association between environmental attitudes and pro-environmental behavior: A multilevel regression approach. J. Clean. Prod. 2018, 175, 155-163. [CrossRef]

64. Zhang, C.X.; Pearce, P.; Chen, G. Not losing our collective face: Social identity and Chinese tourists' reflections on uncivilised behavior. Tour. Manag. 2019, 73, 71-82. [CrossRef]

65. Zhang, C.; Xiao, H. Destination development in China: Towards an effective model of explanation. J. Sustain. Tour. 2014, 22, 214-233. [CrossRef]

66. Chen, G.; Huang, S.; Bao, J. The multiple logics of tourism development in China. J. Sustain. Tour. 2016, 24, 1655-1673. [CrossRef]

(C) 2020 by the authors. Licensee MDPI, Basel, Switzerland. This article is an open access article distributed under the terms and conditions of the Creative Commons Attribution (CC BY) license (http://creativecommons.org/licenses/by/4.0/). 